\title{
Serum Adropin Levels Are Reduced in Adult Patients with Nonalcoholic Fatty Liver Disease
}

\author{
Orkide Kutlu $^{a}$ Özgür Altun ${ }^{a} \quad$ Okan Dikker $^{b}$ Şerife Aktaş ${ }^{c}$ Neslihan Özsoy ${ }^{a}$ \\ Yücel Arman ${ }^{a}$ Eylem Özgün Çil ${ }^{a}$ Mustafa Özcan ${ }^{a}$ Şengül Aydın Yoldemira \\ Murat Akarsu $^{a}$ Illkim Deniz Toprak ${ }^{a}$ Kerem Kırnad Yasin Kutlu ${ }^{a}$ Zeki Toprak ${ }^{e}$ \\ Hasan Eruzun ${ }^{a}$ Tufan Tükek ${ }^{f}$ \\ anternal Medicine Department, Okmeydanı Training and Research Hospital, Istanbul, Turkey; ${ }^{b}$ Medical \\ Biochemistry Department, Okmeydanı Training and Research Hospital, Istanbul, Turkey; ${ }^{C}$ Internal Medicine \\ Department, Umraniye Training and Research Hospital, Istanbul, Turkey; ${ }^{d}$ Internal Medicine Department, Haseki

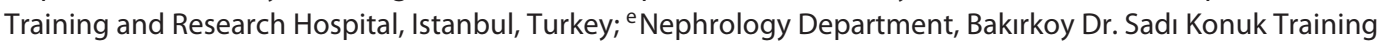 \\ and Research Hospital, Istanbul, Turkey; Internal Medicine Department, Istanbul Faculty of Medicine, Istanbul \\ University, Istanbul, Turkey
}

\section{Significance of the Study}

- Adropin is a newly defined peptide hormone with essential roles in metabolic homeostasis, such as controlling fatty acid metabolism and prevention of insulin resistance. This study evaluates the relationship between nonalcoholic fatty liver disease and adropin in adults. We suggest that adropintargeted studies will contribute to the prevention or treatment of metabolic diseases in the future.

\section{Keywords}

Hepatosteatosis · Adropin · Liver disease

\begin{abstract}
Objectives: Adropin is a novel marker of metabolic syndrome and insulin resistance. The aim of this study was to explore the association of serum adropin levels with hepatosteatosis among adult patients. Materials and Methods: Serum biochemical parameters including liver and renal function tests, insulin levels, and serum adropin levels were compared between adult patients with nonalcoholic fatty liver disease (NAFLD) and healthy control cases. Results: A
\end{abstract}

\section{KARGER}

E-Mail karger@karger.com www.karger.com/mpp
(C) 2019 The Author(s) Published by S. Karger AG, Basel

Karger

Open access

This is an Open Access article licensed under the Creative Commons Attribution-NonCommercial-4.0 International License (CC BY-NC) (http://www.karger.com/Services/OpenAccessLicense), applicable to the online version of the article only. Usage and distribution for commercial purposes requires written permission. total of 51 patients with a mean age of $37.9 \pm 9.96$ years diagnosed with grade 2-3 hepatosteatosis and 30 healthy control cases with a mean age of $34.8 \pm 9.5$ years were included in the study. Serum adropin levels in the NAFLD group were statistically significantly lower than in the control cases (588.4 \pm 261.0 vs. $894.2 \pm 301.2$, respectively; $p<$ 0.001 ). The study participants were further subdivided into 2 groups as patients with $(n=35)$ or without $(n=46)$ insulin resistance using the serum homeostatic model of assessment-insulin resistance (HOMA-IR). Serum adropin levels were statistically significantly lower in patients with insulin resistance $(p<0.01)$. There was a negative correlation between adropin levels and serum insulin, HOMA-IR, urea, 
gamma-glutamyl transferase, total cholesterol, and triglyceride levels. Conclusion: We observed a decrease in serum adropin levels among adult patients with NAFLD. We also found lower levels of serum adropin in patients with insulin resistance, supporting previous data in the literature. Studies investigating the association of adropin levels with other inflammatory parameters are warranted to define its exact role in the pathogenesis of hepatosteatosis.

(C) 2019 The Author(s)

Published by S. Karger AG, Basel

\section{Introduction}

Nonalcoholic fatty liver disease (NAFLD) is defined as the presence of hepatic steatosis in the absence of any other causes of chronic liver disease, alcohol consumption, or treatment with steatogenic medications. It comprises a wide spectrum of histological alterations ranging from simple fatty infiltration to nonalcoholic steatohepatitis and cirrhosis [1]. NAFLD is the most common chronic liver disease in developed countries, affecting approximately $34-46 \%$ of the general population $[2,3]$. The pathogenesis of NAFLD has not been clearly elucidated yet; however, some mechanisms have been proposed, these include: disturbances in adipocytokine regulation, increase in free fatty acid synthesis, and de novo lipogenesis in hepatocytes, inhibition of synthesis of apolipoprotein B-100, disturbances in beta-oxidation of fatty acid and augmented oxidative stress, insulin resistance, and inflammation [3-5]. NAFLD is regarded as the liver presentation of metabolic syndrome, which is associated with obesity, insulin resistance, type 2 diabetes, and/or dyslipidemia [6].

Adropin is a 76-amino acid peptide encoded by the energy homeostasis-associated (Enho) gene. Adropin was first identified by Kumar et al. [7] in liver and brain tissues of rats. This peptide was later also determined to be present in the heart, intestine, kidney, pancreas, umbilical vein, salivary glands, some peripheral tissues, and plasma $[8,9]$. Adropin is a regulator in obesity-associated hyperinsulinemia, lipid/glucose homeostasis, and energy metabolism. Its secretion is mediated by dietary macronutrients [7]. In experimental studies, systemic injections of adropin have been shown to improve skeletal muscle insulin sensitivity and to promote weight loss [10]. Adropin has been shown in the literature to be decreased in many diseases, such as type 2 diabetes, diabetic nephropathies, coronary atherosclerosis, hypertension, and polycystic ovary disease [11-14].
Serum levels of adropin were shown to be decreased among pediatric adolescent patients with NAFLD [15]. However, data on adropin levels in pediatric and adult patients with NAFLD are limited. The aim of this study was to determine the association of adropin with hepatosteatosis in adult patients. We also aimed to investigate its association with insulin resistance. We hypothesized that adropin levels are also decreased among adult patients with NAFLD and insulin resistance.

\section{Materials and Methods}

Study Design and Subjects

Fifty-one consecutive patients admitted to the Internal Medicine department and diagnosed by ultrasound with grade $2-3$ hepatosteatosis were included in this study. Thirty consecutive patients without any known chronic diseases who were shown not to have hepatosteatosis were included as the control group. Patients with chronic diseases such as diabetes mellitus or hypertension, postmenopausal women, pregnant women, patients on steroid treatment, patients diagnosed with malignancy, and obese patients with a body mass index $(\mathrm{BMI})>30$ were excluded from the study.

The age, gender, weight, height, medical history, and smoking history of the patients were recorded. Blood samples were obtained after overnight fasting, and laboratory data, including serum glucose, urea, creatinine, aspartate aminotransferase, alanine aminotransferase, gamma-glutamyl transferase (GGT), alkaline phosphatase, calcium, C-reactive protein (CRP), sedimentation, complete blood count, total cholesterol, triglyceride, high-density lipoprotein-cholesterol, low-density lipoprotein cholesterol, thyroid-stimulating hormone, and insulin levels, were recorded. During the routine blood tests, one more biochemical tube blood was obtained from the study participants that was centrifuged at 4,000 $\mathrm{rpm}$ for $10 \mathrm{~min}$ and the obtained sera were preserved at $-80^{\circ} \mathrm{C}$.

The BMI of the participants was calculated as weight $(\mathrm{kg}) /$ height squared $\left(\mathrm{m}^{2}\right)$. The insulin resistance of the patients was calculated using the homeostatic model of assessment-insulin resistance (HOMA-IR) formula: HOMA-IR = [fasting serum insulin $(\mu \mathrm{IU} / \mathrm{mL}) \times$ fasting serum glucose $(\mathrm{mg} / \mathrm{dL}) / 405]$. Diagnosis of NAFLD was performed based on increased echogenicity via ultrasound, compatible with fatty infiltration of the liver, by an experienced radiologist [16].

\section{Measurement of Serum Levels of Adropin}

For the measurement of adropin levels, enzyme-linked immunosorbent assay (ELISA) kits (Human AD [Adropin], ELISA Kit Synonyms: ENHO, Energy Homeostasis Associated, Catalog No. E-EL-H5307; Elabscience ${ }^{\mathbb{R}}$, China) were used. The analytical (linear) detection range was $12.50-800 \mathrm{pg} / \mathrm{mL}$ for adropin. The minimal detection limit was $7.50 \mathrm{pg} / \mathrm{mL}$. The reported intra- and interassay CVs were 4.78 and $4.38 \%$, respectively.

\section{Statistical Analysis}

The IBM SPSS statistical program (v.20.0; SPSS Inc., Chicago, IL, USA) was used for the statistical analyses. The parametric variables are expressed as the mean \pm standard deviation, while categorical variables are expressed as percentages. The distribution of 
Table 1. Demographic and laboratory data of the study participants

\begin{tabular}{lccl}
\hline & $\begin{array}{l}\text { Hepatosteatosis } \\
\text { group } \\
(n=51)\end{array}$ & $\begin{array}{l}\text { Controls } \\
(n=30)\end{array}$ & $p$ \\
\hline Age, years & $37.9 \pm 9.96$ & $34.8 \pm 9.5$ & 0.170 \\
Male/female & $26 / 25$ & $14 / 16$ & ns \\
BMI & $29.2 \pm 5.2$ & $27.8 \pm 4.9$ & ns \\
Adropin, pg/mL & $588.4 \pm 261.8$ & $894.2 \pm 301.2$ & $<0.001$ \\
Glucose, mg/dL & $93.8 \pm 9.8$ & $89.2 \pm 10.2$ & 0.048 \\
Insulin, $\mu$ IU/mL & $17.1 \pm 12.3$ & $9.3 \pm 6.1$ & $<0.001$ \\
Total cholesterol, mg/dL & $209.2 \pm 39.9$ & $192.2 \pm 43.3$ & 0.076 \\
HDL-C, mg/dL & $45.6 \pm 17.7$ & $49.6 \pm 12.07$ & 0.223 \\
LDL-C, mg/dL & $131.7 \pm 39.8$ & $117.9 \pm 36.5$ & 0.119 \\
Triglyceride, mg/dL & $158.5 \pm 46.4$ & $118.4 \pm 59.8$ & 0.001 \\
Creatinine, mg/dL & $0.73 \pm 0.19$ & $0.77 \pm 0.14$ & 0.294 \\
AST, IU/L & $22.9 \pm 10.5$ & $20.4 \pm 10.2$ & 0.302 \\
ALT, U/L & $24.1 \pm 12.7$ & $22.2 \pm 26.1$ & 0.648 \\
GGT, IU/L & $25.7 \pm 19.0$ & $21.2 \pm 14.8$ & 0.264 \\
HOMA-IR & $4.1 \pm 2.8$ & $1.60 \pm 0.78$ & $<0.001$ \\
\hline
\end{tabular}

HDL-C, high-density lipoprotein cholesterol; LDL-C, low-density lipoprotein cholesterol; AST, aspartate aminotransferase; ALT, alanine aminotransferase; GGT, gamma-glutamyl transferase; HOMA-IR, homeostatic model of assessment-insulin resistance; ns, not significant.

data was tested for normality with the Kolmogorov-Smirnov test. For the comparison of parametric data between 2 independent groups, an independent sample $t$ test was performed. For data that were not normally distributed, the analysis was performed with the Mann-Whitney U test. The correlations between adropin and other parameters were analyzed by the Spearman test. A $p$ value $<0.05$ was regarded as statistically significant.

\section{Results}

Fifty-one patients ( 25 female, 26 male) diagnosed with grade $2-3$ hepatosteatosis and 30 healthy control cases (16 female, 14 male) were included in the study. The demographical and laboratory data of the study participants are summarized in Table 1. Serum adropin levels in the NAFLD group were statistically significantly lower than those of control cases $(p<0.001)$. Serum triglyceride $(p<$ $0.001)$, insulin $(p<0.001)$, glucose $(p=0.048)$, and HOMA-IR $(p<0.001)$ levels were statistically significantly higher in the NAFD group than in the control group (Table 1).

The study participants were further divided into 2 groups as patients with insulin resistance $(n=35)$ and those without insulin resistance $(n=46)$ based on the HOMA-IR levels. The comparisons of these groups are
Table 2. Demographic and laboratory data of the study participants regarding the presence of insulin resistance

\begin{tabular}{lccl}
\hline & $\begin{array}{l}\text { Patients with } \\
\text { insulin resistance } \\
(\text { HOMA-IR }>2.7)\end{array}$ & $\begin{array}{l}\text { Patients without } \\
\text { insulin resistance } \\
\text { (HOMA-IR }<2.7)\end{array}$ & \\
& $n=35$ & $n=46$ & \\
& $38.1 \pm 10.6$ & $35.7 \pm 9.2$ & 0.279 \\
Age, years & $17 / 18$ & $23 / 23$ & ns \\
Male/female & $29.4 \pm 5.3$ & $28.1 \pm 4.8$ & $n s$ \\
BMI & $600 \pm 271$ & $778 \pm 323$ & 0.010 \\
Adropin, pg/mL & $96.5 \pm 9.4$ & $88.7 \pm 9.4$ & $<0.001$ \\
Glucose, mg/dL & $22.8 \pm 12.2$ & $7.6 \pm 2.3$ & $<0.001$ \\
Insulin, $\mu \mathrm{IU} / \mathrm{mL}$ & $208.5 \pm 38.5$ & $198.7 \pm 44.1$ & 0.299 \\
Total cholesterol, mg/dL & $47.7 \pm 13.9$ & $46.6 \pm 13.9$ & 0.746 \\
HDL-C, mg/dL & $131 \pm 33.8$ & $123 \pm 41.5$ & 0.372 \\
LDL-C, mg/dL & $145 \pm 44.4$ & $142 \pm 62.3$ & 0.836 \\
Triglyceride, mg/dL & $35.02 \pm 15.5$ & $28.9 \pm 12.1$ & 0.051 \\
Urea, mg/dL & $0.77 \pm 0.16$ & $0.72 \pm 0.18$ & 0.235 \\
Creatinine, mg/dL & $25.4 \pm 10.7$ & $19.4 \pm 9.5$ & 0.011 \\
AST, IU/L & $24.6 \pm 10.4$ & $22.4 \pm 22.8$ & 0.597 \\
ALT, IU/L & $29.08 \pm 19.03$ & $20.3 \pm 15.6$ & 0.025 \\
GGT, IU/L & $77.6 \pm 34.9$ & $69.1 \pm 28.7$ & 0.292 \\
ALP, IU/L & & & \\
\hline
\end{tabular}

HDL-C, high-density lipoprotein cholesterol; LDL-C, low-density lipoprotein cholesterol; AST, aspartate aminotransferase; ALT, alanine aminotransferase; GGT, gamma-glutamyl transferase; ALP, alkaline phosphatase; HOMA-IR, homeostatic model of assessment-insulin resistance; ns, not significant.

summarized in Table 2. Serum adropin levels were statistically significantly lower in patients with insulin resistance $(p<0.01$; Table 2$)$.

The results of the correlation analysis of serum adropin levels with other parameters are summarized in Table 3. A negative correlation was observed between adropin levels and serum insulin, HOMA-IR, urea, GGT, total cholesterol, and triglyceride levels (Table 3; Fig. 1, 2).

\section{Discussion}

We determined statistically significantly lower serum levels of adropin in patients with hepatosteatosis compared to healthy controls cases. Moreover, adropin levels were significantly lower in patients with insulin resistance. It is not surprising that parameters of insulin resistance and metabolic syndrome were significantly higher in the patients with hepatosteatosis compared with the healthy control cases. To the best of our knowledge, this is the first study to report the association of serum levels of adropin with insulin resistance and NAFLD in adult patients. 
Table 3. The results of correlation analysis between serum adropin levels and other parameters in the hepatosteatosis group (nonparametric Spearman's correlation analysis)

\begin{tabular}{|c|c|c|c|c|c|c|c|c|c|}
\hline & HOMA-IR & Insulin & GGT & $\begin{array}{l}\text { Total } \\
\text { cholesterol }\end{array}$ & $\begin{array}{l}\text { LDL- } \\
\text { C }\end{array}$ & $\begin{array}{l}\text { HDL- } \\
\mathrm{C}\end{array}$ & Triglyceride & AST & ALT \\
\hline Adropin & $\begin{array}{r}-0.241 \\
0.030\end{array}$ & $\begin{array}{r}-0.233 \\
0.036\end{array}$ & $\begin{array}{r}-0.271 \\
0.014\end{array}$ & $\begin{array}{r}-0.229 \\
0.040\end{array}$ & $\begin{array}{r}-0.215 \\
0.054\end{array}$ & $\begin{array}{l}0.152 \\
0.177\end{array}$ & $\begin{array}{r}-0.302 \\
0.006\end{array}$ & $\begin{array}{r}-0.145 \\
0.197\end{array}$ & $\begin{array}{c}-0.63 \\
0.578\end{array}$ \\
\hline
\end{tabular}

$r$, correlation coefficient; $p$, significance; HDL-C, high-density lipoprotein cholesterol; LDL-C, low-density lipoprotein cholesterol; AST, aspartate aminotransferase; ALT, alanine aminotransferase; GGT, gamma-glutamyl transferase; HOMA-IR, homeostatic model of assessment-insulin resistance.

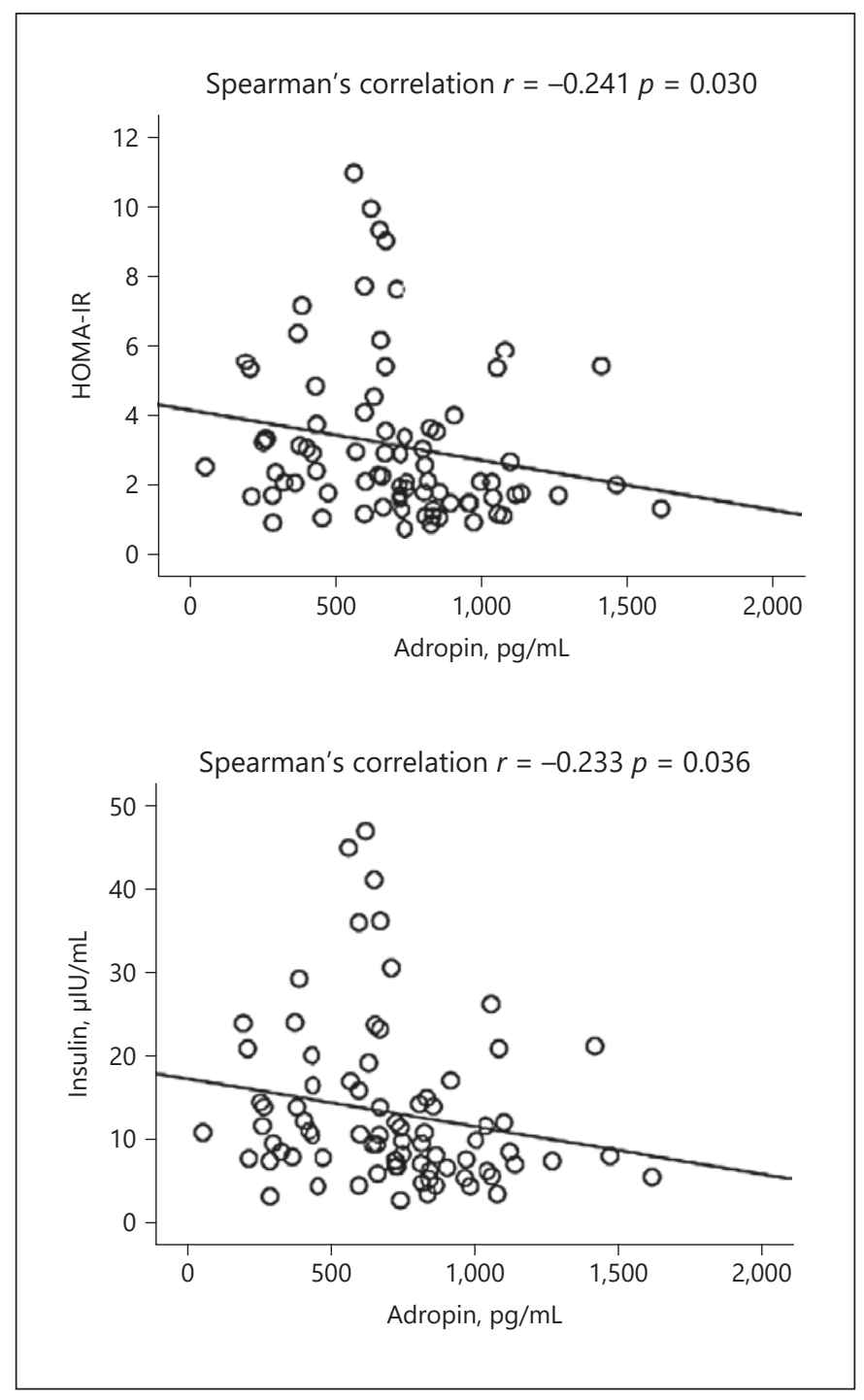

Fig. 1. Correlation analysis between serum levels of adropin and HOMA-IR and insulin levels in the hepatosteatosis group.

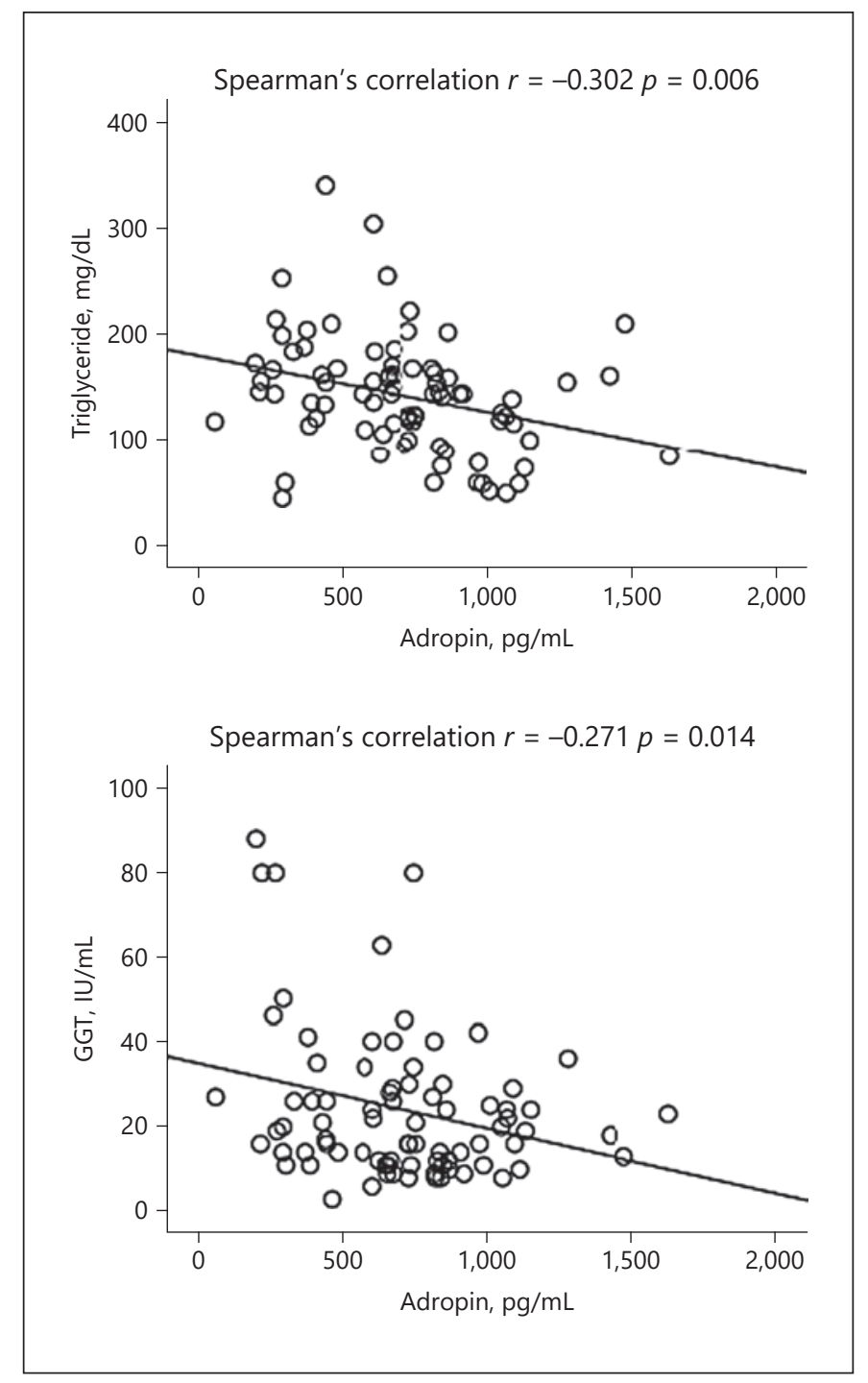

Fig. 2. Correlation analysis between serum levels of adropin and triglyceride and GGT levels in the hepatosteatosis group. 
Some mechanisms are suggested to define the association of insulin resistance with metabolic disorders, such as disturbances in hypothalamic centers of energy homeostasis, impaired peroxisome proliferator-activated receptor gamma (PPAR- $\gamma$ ) activation, endothelial dysfunction, and inflammation, as have been mentioned elsewhere $[17,18]$. As these metabolic disorders are very common [2], it is important to define the molecules that play a role in the pathogenesis, and thus determine the new therapeutic targets.

Adropin is a newly defined peptide hormone with important roles in metabolic homeostasis, such as controlling fatty acid metabolism and preventing insulin resistance, dyslipidemia, and impaired glucose tolerance. Recently, plasma adropin levels were reported to be lower in patients with metabolic syndrome compared with healthy obese subjects or those with normal weights [19]. Some mechanisms are suggested to define the role of adropin in metabolic syndrome-associated diseases. In an experimental study, synthetic adropin was determined to augment the total lipoprotein lipase (LPL) production and secretion in hepatocyte cultures [20]. LPL is located at the capillary endothelium and it catalyzes the hydrolysis of endogenous and exogenous triacylglycerol complexes to glycerol and free fatty acids, and for that reason it plays an essential role in the clearance of triacylglycerol-rich plasma lipoproteins. LPL is thus suggested to be a protective factor in NAFLD, and adropin is suggested to increase the production of this protective factor $[20,21]$.

NAFLD has been reported to be associated with endothelial dysfunction [22]. Interestingly, Baka et al. [23] reported increased maternal levels of adropin in severe intrauterine fetal growth restriction, which might represent a regulatory feedback mechanism against endothelial placental dysfunction. Endothelial functions that are also important in metabolic regulations and insulin sensitivity are mainly regulated by nitric oxide synthesis [24]. The expression of endothelial nitric oxide synthetase was shown to be induced by adropin, and adropin deficiency was reported to be associated with decreased nitric oxide levels in endothelial cells $[8,25]$. On the other hand, adropin was also associated with the expression of hepatic lipogenic genes and adipose tissue PPAR- $\gamma$, which is a nuclear receptor with a major role in the regulation of energy homeostasis and metabolic functions. Through induced nitric oxide synthesis and regulation of PPAR- $\gamma$ receptor activation, adropin may be suggested as being a director in energy metabolism and endothelial functions $[7,26]$. In the development and pro- gression of NAFLD, the role of inflammation is obvious. However, the data on the association of adropin with inflammation is limited. A study by $\mathrm{Wu}$ et al. [12] showed a negative correlation between adropin and levels of CRP. Adropin may be suggested as a potential anti-inflammatory protein, with a protective role in inflammation-related metabolic diseases.

We found only one study on adropin and fatty liver disease in the pediatric age group. Sayın et al. [15] compared 64 obese adolescent patients (30 with NAFLD, 34 without NAFLD) with 36 healthy control cases and showed that serum levels of adropin were significantly lower in patients with NAFLD than both obese patients without NAFLD and healthy controls. Moreover, in a logistic regression analysis, lower serum adropin levels were reported as the only independent risk factor for hepatosteatosis, and the authors suggested serum adropin levels as a marker of NAFLD in adolescents. Similarly, in adult patients, we also determined significantly lower serum adropin levels in the NAFLD group compared to healthy controls.

Diets rich in fat but low in carbohydrates were shown to cause an increase in levels of adropin, while diets rich in simple carbohydrates were determined to cause a decrease in serum adropin levels and to enhance obesity [27]. In another experimental study, adropin-deficient rats with the presence of insulin resistance and dyslipidemia were reported to have high lipid and triglyceride contents in liver tissues, and in that study hyperinsulinemia was reported to be associated with hepatic lipogenesis [24]. In our study, consistent with previous experimental studies, patients with insulin resistance were found to have lower serum adropin levels compared with patients without insulin resistance.

Kałużna et al. [28] reported a negative correlation between adropin levels and the BMI of patients. Moreover, Butler et al. [29] reported an increase in serum adropin concentrations after gastric bypass surgery. In that study the mean BMI of the participants was $37-65$, which was very high compared to our study. Adropin concentrations were reported to be increased after Roux-en-Y gastric bypass, reaching a peak 3 months after surgery. However, we did not evaluate serum adropin concentrations in patients with different BMI levels, which is a limitation of our study.

Interestingly, in an experimental study in mice, Gao et al. [10] reported an improvement in glucose tolerance and a decrease in insulin resistance with adropin treatment. Moreover, in a study by Akcilar et al. [30], adropin administration caused a decrease in blood glu- 
cose levels and an improvement in insulin resistance in rats with streptozocin-induced diabetes mellitus. In the light of these data, adropin may be regarded as a potential target for the treatment of metabolic disturbances associated with insulin resistance. In addition, studies on the role of adropin in the treatment of NAFLD are warranted.

In this study we determined a negative correlation between levels of adropin and total cholesterol and triglyceride levels. The role of adropin in the development of obesity is still not clear [31]. If there is a casual association, then administration of adropin, or pharmaceuticals that promote its production, may be a novel approach in the treatment or prevention of dyslipidemia, obesity, or metabolic syndrome development.

One limitation of this study is the lack of comparison of different BMI groups, as mentioned above. A second is that some other adipokines and pro-inflammatory cytokines were not studied, nor was the correlation of oxidant-antioxidant status with adropin levels.

\section{Conclusion}

We determined a decrease in serum adropin levels among adult patients with NAFLD compared with healthy controls. We also found lower levels of serum adropin in patients with insulin resistance. Studies investigating the association of adropin with other inflammatory parameters are warranted to define its exact role in the pathogenesis of hepatosteatosis. Its role in the treatment of NAFLD should also be explored.

\section{Statement of Ethics}

The study protocol was designed in compliance with the Declaration of Helsinki. The study was approved by the local ethics committee. Informed consent was obtained from all study participants.

\section{Disclosure Statement}

The authors have no conflicts of interest to disclose.

\section{References}

1 Kitade H, Chen G, Ni Y, Ota T. Nonalcoholic fatty liver disease and insulin resistance: new insights and potential new treatments. Nutrients. 2017 Apr;9(4):387.

2 Williams CD, Stengel J, Asike MI, Torres DM, Shaw J, Contreras M, et al. Prevalence of nonalcoholic fatty liver disease and nonalcoholic steatohepatitis among a largely middle-aged population utilizing ultrasound and liver biopsy: a prospective study. Gastroenterology. 2011 Jan;140(1):124-31.

3 Ahmed A, Wong RJ, Harrison SA. Nonalcoholic fatty liver disease review: diagnosis, treatment, and outcomes. Clin Gastroentero Hepatol. 2015 Nov;13(12):2062-70.

4 McClain CJ, Mokshagundam SP, Barve SS, Song Z, Hill DB, Chen T, et al. Mechanisms of non-alcoholic steatohepatitis. Alcohol. 2004 Aug;34(1):67-79.

5 Tilg H, Moschen AR. Evolution of inflammation in nonalcoholic fatty liver disease: the multiple parallel hits hypothesis. Hepatology. 2010 Nov;52(5):1836-46.

6 Haas JT, Francque S, Staels B. Pathophysiology and mechanisms of nonalcoholic fatty liver disease. Annu Rev Physiol. 2016;78(1): 181-205.

7 Kumar KG, Trevaskis JL, Lam DD, Sutton GM, Koza RA, Chouljenko VN, et al. Identification of adropin as a secreted factor linking dietary macronutrient intake with energy homeostasis and lipid metabolism. Cell Metab. 2008 Dec;8(6):468-81.
8 Lovren F, Pan Y, Quan A, Singh KK, Shukla $\mathrm{PC}$, Gupta M, et al. Adropin is a novel regulator of endothelial function. Circulation. 2010 Sep;122(11 Suppl):S185-92.

9 Aydin S, Kuloglu T, Aydin S, Eren MN, Yilmaz M, Kalayci M, et al. Expression of adropin in rat brain, cerebellum, kidneys, heart, liver, and pancreas in streptozotocininduced diabetes. Mol Cell Biochem. 2013 Aug;380(1-2):73-81.

10 Gao S, McMillan RP, Zhu Q, Lopaschuk GD, Hulver MW, Butler AA. Therapeutic effects of adropin on glucose tolerance and substrate utilization in diet-induced obese mice with insulin resistance. Mol Metab. 2015 Jan;4(4): $310-24$.

$11 \mathrm{Hu}$ W, Chen L. Association of serum adropin concentrations with diabetic nephropathy. Mediators Inflamm. 2016;2016:6038261.

12 Wu L, Fang J, Chen L, Zhao Z, Luo Y, Lin C, et al. Low serum adropin is associated with coronary atherosclerosis in type 2 diabetic and non-diabetic patients. Clin Chem Lab Med. 2014 May;52(5):751-8.

13 Topuz M, Celik A, Aslantas T, Demir AK, Aydin S, Aydin S. Plasma adropin levels predict endothelial dysfunction like flow-mediated dilatation in patients with type 2 diabetes mellitus. J Investig Med. 2013 Dec;61(8): $1161-4$.
14 Kume T, Calan M, Yilmaz O, Kocabas GU, Yesil P, Temur M, et al. A possible connection between tumor necrosis factor alpha and adropin levels in polycystic ovary syndrome. J Endocrinol Invest. 2016 Jul;39(7):747-54.

15 Sayın O, Tokgöz Y, Arslan N. Investigation of adropin and leptin levels in pediatric obesityrelated nonalcoholic fatty liver disease. J Pediatr Endocrinol Metab. 2014 May;27(5-6): 479-84.

16 Quinn SF, Gosink BB. Characteristic sonographic signs of hepatic fatty infiltration. AJR Am J Roentgenol. 1985 Oct;145(4):753-5.

17 Abenavoli L, Milic N, Di Renzo L, Preveden T, Medić-Stojanoska M, De Lorenzo A. Metabolic aspects of adult patients with nonalcoholic fatty liver disease. World J Gastroenterol. 2016 Aug;22(31):7006-16.

18 Loomba R, Abraham M, Unalp A, Wilson L, Lavine J, Doo E, et al.; Nonalcoholic Steatohepatitis Clinical Research Network. Association between diabetes, family history of diabetes, and risk of nonalcoholic steatohepatitis and fibrosis. Hepatology. 2012 Sep;56(3): 943-51.

19 Mierzwicka A, Bolanowski M. New peptides players in metabolic disorders. Postepy Hig Med Dosw. 2016 Aug;70(0):881-6.

20 Lian A, Wu K, Liu T, Jiang N, Jiang Q. Adropin induction of lipoprotein lipase expression in tilapia hepatocytes. J Mol Endocrinol. 2016 Jan;56(1):11-22. 
21 Wang H, Eckel RH. Lipoprotein lipase: from gene to obesity. Am J Physiol Endocrinol Metab. 2009 Aug;297(2):E271-88.

22 Verma S, Buchanan MR, Anderson TJ. Endothelial function testing as a biomarker of vascular disease. Circulation. 2003 Oct;108(17): 2054-9.

23 Baka S, Malamitsi-Puchner A, Briana DD, Boutsikou M, Marmarinos A, Gourgiotis D, et al. Adropin concentrations in term pregnancies with normal, restricted and increased fetal growth. J Matern Fetal Neonatal Med. 2016;29(15):2403-7.

24 Mather KJ, Lteif A, Steinberg HO, Baron AD. Interactions between endothelin and nitric oxide in the regulation of vascular tone in obesity and diabetes. Diabetes. 2004 Aug; 53(8):2060-6.
25 Ganesh Kumar K, Zhang J, Gao S, Rossi J, McGuinness OP, Halem HH, et al. Adropin deficiency is associated with increased adiposity and insulin resistance. Obesity (Silver Spring). 2012 Jul;20(7):1394-402.

26 Tyagi S, Gupta P, Saini AS, Kaushal C, Sharma $\mathrm{S}$. The peroxisome proliferator-activated receptor: A family of nuclear receptors role in various diseases. J Adv Pharm Technol Res. 2011 Oct;2(4):236-40.

27 St-Onge MP, Shechter A, Shlisky J, Tam CS, Gao S, Ravussin E, et al. Fasting plasma adropin concentrations correlate with fat consumption in human females. Obesity (Silver Spring). 2014 Apr;22(4):1056-63.

28 Kałużna M, Hoppe K, Schwermer K, Ibrahim AY, Pawlaczyk K, Ziemnicka K. Adropin and irisin levels in relation to nutrition, body composition, and insulin resistance in patients with end-stage renal disease on chronic hemodialysis and peritoneal dialysis. $\mathrm{Pol}$ Arch Med Wewn. 2016 Jul;126(7-8):474-82.
29 Butler AA, Tam CS, Stanhope KL, Wolfe BM, Ali MR, O'Keeffe M, et al. Low circulating adropin concentrations with obesity and aging correlate with risk factors for metabolic disease and increase after gastric bypass surgery in humans. J Clin Endocrinol Metab. 2012 Oct;97(10):3783-91.

30 Akcilar R, Kocak FE, Simsek H, Akcilar A, Bayat Z, Ece E, et al. Antidiabetic and hypolipidemic effects of adropinin streoptozotocin-induced type 2 diabetic rats. Bratisl Lek Listy. 2016;117(2):100-5.

31 Chang JB, Chu NF, Lin FH, Hsu JT, Chen PY. Relationship between plasma adropin levels and body composition and lipid characteristics amongst young adolescents in Taiwan. Obes Res Clin Pract. 2018 Jan - Feb;12(1 Suppl 2):101-7. 